\title{
An Unusual Case of Cardiomyopathy in a Child
}

\section{Jayapalan Dinesh kumar ${ }^{1} \cdot$ Sangeetha Geminiganesan ${ }^{1} \cdot$ Ramachandran Padmanaban $^{1} \cdot$ Subbarao Pinnaka ${ }^{1}$. Thirugnanasmambandam Chandrasekar ${ }^{1}$}

Received: 28 July 2019 / Accepted: 17 September 2019 / Published online: 13 November 2019

(C) Dr. K C Chaudhuri Foundation 2019

To the Editor: Drug reaction with eosiniphilia and systemic symptoms (DRESS syndrome) is a life-threatening adverse condition following most common offending drugs like anticonvulsants and sulfonamides [1].

An 8-y-old boy was started on prophylactic phenytoin who had extradural hemorrhage following head injury. A month later, he presented with fever, rash, eosinophilia, elevated transaminases and DRESS syndrome was diagnosed after ruling other etiologies. He was started on methyl prednisolone for $5 \mathrm{~d}$ followed by oral steroids over $2 \mathrm{wk}$. A month later, the child developed myocarditis and severe left ventricle dysfunction with low ejection fraction (EF). He was treated appropirately. Myocarditis secondary to DRESS was suspected and he was started again on methyl prednisolone along with aspirin and enalapril. Repeat ECHO showed improvement in ejection fraction and the boy was discharged with oral steroids for $6 \mathrm{wk}$. At 6th wk, he presented again with left ventricular (LV) failure symptoms with low EF and was started again with steroids and given 2 doses of immunoglobulin $2 \mathrm{~g} / \mathrm{kg}$ at $6 \mathrm{wk}$ interval. Ivabradin and enalapril were given to support the cardiac function. But unfortunately he again had left ventricular failure symptoms with ectopic beats after 3 mo and hence was initiated on levosimendan and carvedilol. During this episode, on tapering steroids, he was initiated on mycophenolate mofetil. The child is stable with Ivabradin and enalapril but continues to have EF of 26 to 30\%. Cardiac transplantation has been given as a choice of management for this boy as he has had recurrent cardiac failure.

DRESS syndrome is characterized by a triad of fever, rash and hepatitis which usually presents 2 to $6 \mathrm{wk}$ after initiation of offending drugs. It is differentiated from other drug reactions by its later onset and severe systemic involvement as in this child.

Immunosuppression with steroids is the cornerstone of treatment and the duration of therapy is between 4 to 6 mo. Cyclosporin, mycophenolate mofetil, azathioprine and rituximab are also considered in severe conditions. Plasma exchange and intravenous immunoglobulins (IVIG) were also used $[2,3]$.

DRESS is a serious consequence of anticonvulsants. The associated cardiac abnormalities require early recognition and supportive therapy. Multidisciplinary care is important for a successful management.

\section{Compliance with Ethical Standards}

Conflict of Interest None.

\section{References}

1. Husain Z, Reddy BY, Schwartz RA. DRESS syndrome. J Am Acad Dermatol. 2013;68:709e1-9.

2. Thacker H, Shah M, Tulle R. DRESS syndrome: drug rash with eosinophilia and systemic symptoms. J Assoc Physicians India. 2015;63:78-9.

3. Thonsgri T, Chularojanamontri L, Pichler WJ. Cardiac involvement in DRESS syndrome. Asian Pac J Allergy Immunol. 2017;35:3-10.

Publisher's Note Springer Nature remains neutral with regard to jurisdictional claims in published maps and institutional affiliations.

Jayapalan Dinesh kumar

drdeenu03@yahoo.com

1 Department of Pediatrics, Sri Ramachandra Institute of Higher Center, Porur, Chennai 600116, India 